\title{
Based on the Secondary Substations Sectional Reactive Compensation Technology Research and Implementation
}

\author{
Haiyan Wang \\ Changchun University of science and technology \\ 13742883@qq.com
}

\begin{abstract}
Large perceptual class motor load is the main production equipment of metallurgical enterprise, although has taken independent secondary substation power supply mode, but due to the influence of the impact load, Often appears on the bus voltage drop and low power factor and harmonic big problems, , this article is based on SVC compensation control mechanism, the sectional control mode, the principle of reactive power compensation and harmonic suppression methods are analyzed, , and designed a set of reactive power compensation and harmonic suppression function of comprehensive compensation device, it has been verified by actual operation, high reactive power compensation and harmonic suppression effect, and effectively suppress the busbar voltage drop and improving the quality of the power supply, created the direct economic benefits for the implementation of the enterprise.
\end{abstract}

Keywords: The perceptual load; Low voltage bus bar; SVC compensator; Sectional control; Electric power quality

\section{Foreword}

Has been the industrial utilization of large metallurgical enterprises, at the same time is also one of the industries that national focus on energy saving and emission reduction. From ore mining to belt transmission, ore material crushing and screening to make iron powder (pellet), tailings recycling, and other production process, used to drive such as crusher, ball mill, the power source of the conveyor belt and other large equipment, all belong to induction ac motor, the power factor of the large lag of motor load of substation (electromagnetic station), the supply network and other electrical equipment connected with network bus particularly outstanding, , although in general the manufacturer in the workshop or process divided into several small power supply area, and set up corresponding independent secondary substations for separate power supply, but the power factor, harmonic and voltage fluctuation on the bus are still problems such as the existence of different level.

To effectively improve power quality, reduce loss and improve circuit and power conversion efficiency and other issues, has long been a national energy conservation development policy in key areas of concern, but also a matter of the benign development of the enterprise a barrier.

A large pellet mill in anshan iron and steel group, responsible for ore crushing process broken power supply substation, use "one with a case of" two step-down transformer (10 $\mathrm{kv} / 380 \mathrm{v}$ ) of the power supply mode, to effectively improve power quality, reduce loss and improve circuit and power conversion efficiency and other issues, has long been a national energy development policy in key areas of concern, but also a matter of the benign development of the enterprise a barrier, Parallel low-voltage busbar, and through the two road, is responsible for carrying out the whole crushing plant mineral material of the conveyor belt motor power supply mission, in the process of ore material transporting work, due to the volatility of mineral loads, taking reactive current of induction motor, down mine materials piled up occasionally, hairpin and mechanical operation of the belt 
uneven wear running deviation, and many other factors, especially on the bus ac motor soft starter, power conversion devices such as frequent bus low power factor, current harmonic content is big, current waveform distortion is serious, increased reactive loss and a series of electric energy quality bad phenomenon. When the manufacturer in substation construction was on the bus is designed and equipped with the low voltage reactive power compensation device, but after a period of operation, found that the device has some following major disadvantages. Namely: (1) with the increase of electricity consumption, the original small compensation capacity; (2) the chosen for control devices are unreasonable; (3) using a single static compensation mode is not perfect; The entrance to the circuit breaker capacity lack (4) devices. 5. Every single supplement branch protection measures; 6 . No harmonic suppression function, etc.

As a result of the existence of these problems, working in close to full capacity, low voltage on the bus once frequent too heavy current harmonic, and voltage balance and power factor is low and so on directly affect the production, and in the manufacturer through research and technical renovation project, analysis established the busbar, loss and compensation of reactive power capacity, and between, surge current and specify harmonic filter reactor function model between [1]; And verify to calculate the maximum load condition of reactive power demand. Based on the apparent power constant reactive power compensation principle and application of power electronic transformation technology method, designed the sectional SVC compensator main structure; And USES the instantaneous power factor detection of busbar feedback closed loop control mode, has developed a set of intelligent reactive power compensation device, reliably realize the reactive power compensation on-spot and specify the harmonics effectively eliminate, greatly improve the power factor of power supply bus and power quality, promote enterprise's energy conservation and emissions reduction work.

\section{Load for Approval and Reactive Power Compensation Capacity Calculation}

Is used by the secondary substations into line $10 \mathrm{kv}$ substation independent power supply at the next higher level, and within the substation with two SCB10-1600/10.5 independent transformer, undertake the task of the secondary variable, two transformer in "one with a prepared" work mode, low voltage output corresponding I and II two low voltage busbar connection respectively different processes of load, the research and development of the two sets of compensation device connected respectively I and II two low pressure on the bus, as shown in Figure 1. 


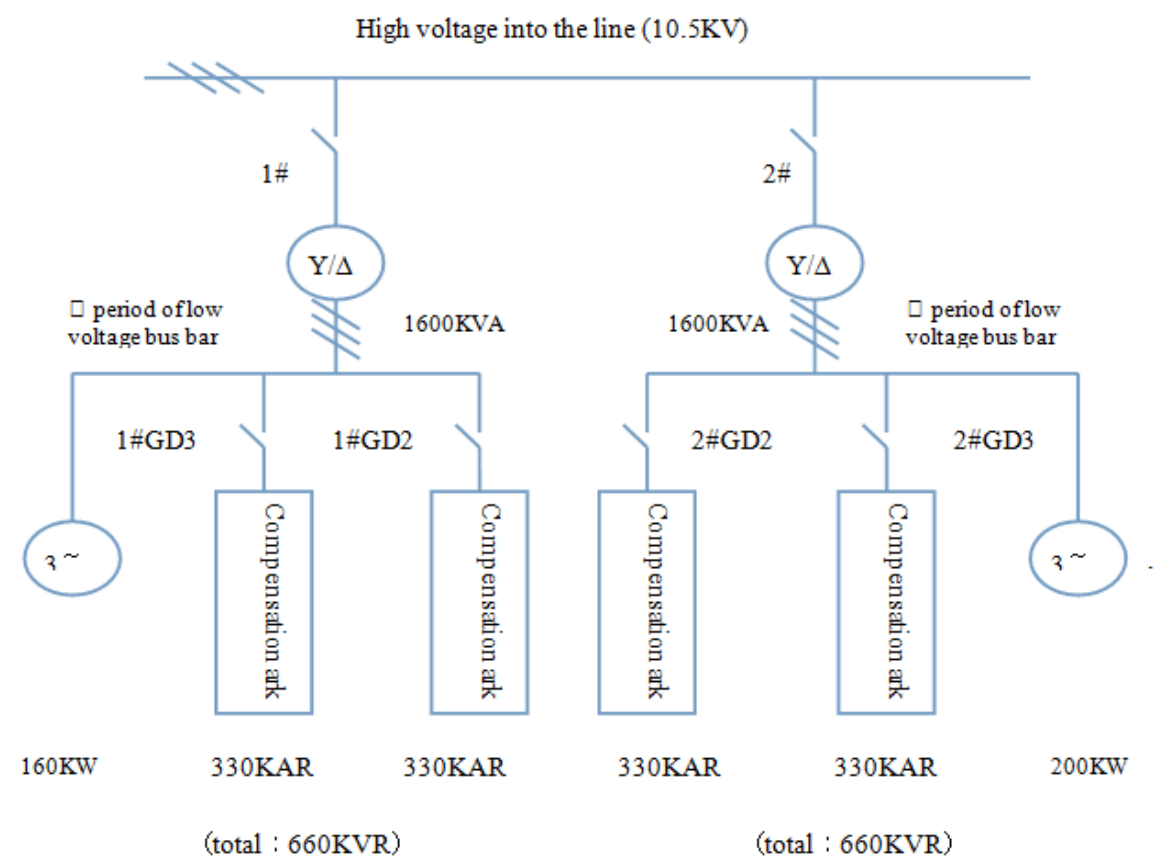

Figure 1. Second Substation Power Supply Diagram

By the second substation power supply load of main motor and feed motor, a belt dusting motor and circulating water pump, etc., the load type and verified by the specific power as shown in Table 1 . Including I and II bus on total load capacity of $959 \mathrm{kw}$ and $1039 \mathrm{kw}$ respectively.

Table 1. I and II Bus Load Configuration and the Power

\begin{tabular}{|c|c|c|c|c|c|}
\hline \multicolumn{3}{|c|}{ I load configuration } & \multicolumn{3}{|c|}{ II load configuration } \\
\hline $\begin{array}{l}\text { the Load } \\
\text { name }\end{array}$ & $\begin{array}{c}\text { Numb } \\
\text { er }\end{array}$ & $\begin{array}{l}\text { Active power } \\
(\mathrm{kW})\end{array}$ & Load name & Number & $\begin{array}{c}\text { Active power } \\
(\mathrm{kW})\end{array}$ \\
\hline $\begin{array}{c}\text { \# belt main } \\
\text { motor }\end{array}$ & 1 & 110 & $\begin{array}{l}8 \# \text { belt main } \\
\text { motor }\end{array}$ & 2 & $2 \times 200$ \\
\hline $\begin{array}{l}\text { 2\# belt main } \\
\text { motor }\end{array}$ & 1 & 132 & $\begin{array}{l}\text { 9\# belt main } \\
\text { motor }\end{array}$ & 1 & 132 \\
\hline $\begin{array}{l}3 \# \text { belt main } \\
\text { motor }\end{array}$ & 2 & $2 \times 160$ & $\begin{array}{l}\text { 16\#belt main } \\
\text { motor }\end{array}$ & 1 & 30 \\
\hline $\begin{array}{l}4 \# \text { belt main } \\
\text { motor }\end{array}$ & 1 & 22 & $\begin{array}{l}\text { 17\#belt main } \\
\text { motor }\end{array}$ & 1 & 132 \\
\hline $\begin{array}{l}5 \# \text { belt main } \\
\text { motor }\end{array}$ & 1 & 160 & $\begin{array}{l}\text { 18\#belt main } \\
\text { motor }\end{array}$ & 1 & 132 \\
\hline Dusting motor & 1 & 90 & $\begin{array}{l}\text { Dusting } \\
\text { motor }\end{array}$ & 1 & 90 \\
\hline Feed motor & 3 & $3 \times 30$ & Feed motor & 3 & $3 \times 30$ \\
\hline
\end{tabular}




\begin{tabular}{|c|c|c|c|c|c|}
\hline $\begin{array}{c}\text { Circulating } \\
\text { water pump }\end{array}$ & 10 & $10 \times 3$ & $\begin{array}{c}\text { Circulating } \\
\text { water pump }\end{array}$ & 10 & $10 \times 3$ \\
\hline Other load & 1 & 5 & Other load & 1 & 3 \\
\hline combined & 21 & 959 & combined & 21 & 1039 \\
\hline
\end{tabular}

For reactive power compensation amount calculated with transformer apparent power constant compensation principle [1], according to the apparent power, active power and reactive power balance of triangular relationship, as shown in Figure 2, the power factor Angle can be obtained by compensate the reactive compensation capacity is necessary to:

$$
Q=k \cdot P \cdot(\tan \varphi-\tan \varphi)
$$

In the type: $\mathrm{Q}$ means to compensate reactive power capacity,

$\mathrm{P}$ said bus output active power, that is, total load capacity.

$\tan \phi, \tan \phi^{\prime}$ respectively before and after the compensation tangent value of the power factor Angle. $\mathrm{K}$ as the correction coefficient, the motor working condition, the degree of compensation, the line loss, load category.

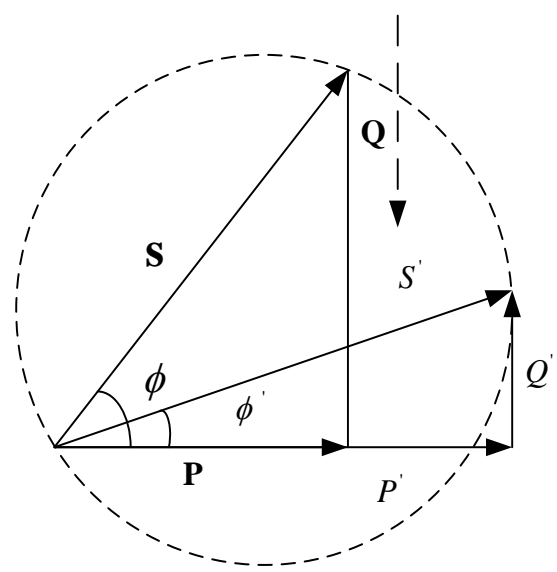

Figure 2. Power Balance between Before and After the Compensation Schemes

Combination of comprehensive analysis of the measured data of transformer substation, the power factor of desirable compensation before as follows: $\cos \varphi=0.78$,that is: ${ }^{\varphi=38.7^{\circ}}$, Assume that the power factor of compensation after: $\cos \varphi^{\prime}=0.95$, that is: $\varphi^{\prime}=18.2^{\circ}$, Consider compensation allowance and load condition factor at the same time, the correction coefficient $k=1.38$, the type (1) can be simplified as:

$Q=k \cdot P \cdot\left(\operatorname{tg} \phi-\operatorname{tg} \phi^{\prime}\right)=0.65187 \cdot P$

Which can be obtained: I busbar, II paragraphs biggest demand of reactive power compensation are:

$$
\begin{gathered}
Q_{1}=0.65187 \times 959=625 \text { KVAR } \\
Q_{2}=0.65187 \times 1039=677 \text { KVAR }
\end{gathered}
$$


For ease of selection of self-healing type low voltage power capacitor in parallel (BSMJ0.4-20-3) device, the comprehensive consideration, take maximum 660 kvar, the reactive compensation capacity that each phase can be composed of 11 power capacitor in parallel.

\section{SVC Compensation Principle}

The main title (on the first page) should begin $13 / 16$ inches ( 7 picas) from the top edge of the page, centered, and in Times New Roman 14-point, boldface type. Capitalize the first letter of nouns, pronouns, verbs, adjectives, and adverbs; do not capitalize articles, coordinate conjunctions, or prepositions (unless the title begins with such a word). Please initially capitalize only the first word in other titles, including section titles and first, second, and third-order headings (for example, "Titles and headings" — as in these guidelines). Leave two blank lines after the title.

TCT static var compensator (SVC) is commonly by multiplex LC reactive power compensation and single tuned filter unit and a set of SCR in series with inductance of TCR and other links, compensator structure as shown in Figure 3. In composed of silicon controlled rectifier, and inductance of TCR branch, by adjusting the silicon controlled rectifier and trigger Angle [2], form continuous adjustable inductance, is used to balance the reactive power. Filter is composed of multiple LC branch, each branch selection of parameters are corresponding to the specified number of harmonic filter, at the same time can also be a controllable capacitive reactive power [3], through the balance of TCR branch to joint the reactive power compensation on the bus. Compensation control system by measuring the instantaneous voltage and current signals on the bus, the microcomputer control, finally produce the thyristor trigger signal, in order to achieve the purpose of the closed loop regulation. In figure $Q_{L} 3^{Q_{L \max }}$ and represent the load of the inductive reactive power and the maximum of the inductive reactive power; when $Q_{C}=Q_{L \max }$, System through the LC resonance branch of capacitive reactive power $Q_{C}$ can separate the biggest perceptual reactive power for the load $Q_{L \max }$ full compensation. Volatility makes the load when the load required reactive power changed from $Q_{L \max }$ to $Q_{L}$, broke the balance between $Q_{C}$ and $Q_{L}$, Will produce $Q_{C}-Q_{L}$ size amount of reactive power deviation, then you need by adjusting A phase ${ }^{T_{b 1}}$ and ${ }^{T_{b 2}}$ of the trigger Angle of silicon controlled rectifier (the other two phase, for that matter), and timely change reactance value $X_{L}, Q_{b}$, perceptual reactive power generated by the TCR branch is used to offset the capacitive reactive power deviation value, thus ensuring the even load fluctuations, also can make the transformer output reactive power on the bus $Q_{S}=Q_{C}-Q_{L}-Q_{b}=0$, better realized the role of in situ reactive compensation [4]. 


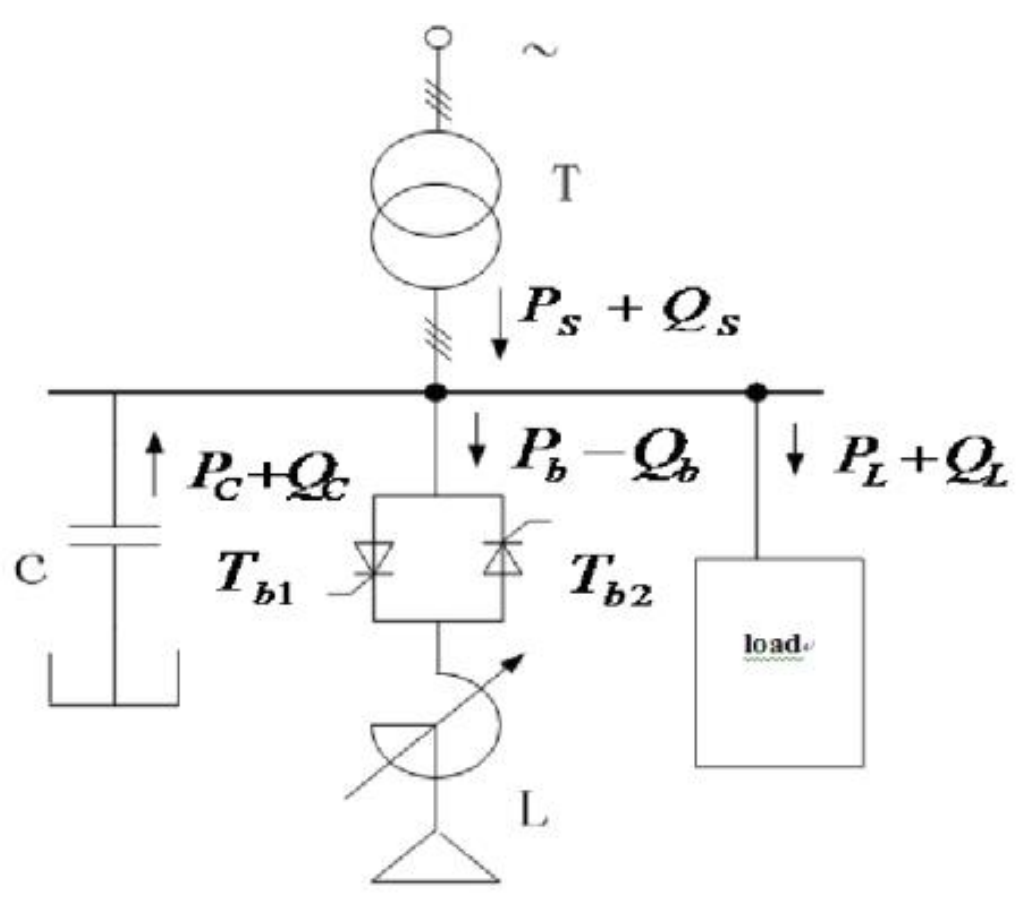

Figure 3. SVC Compensator Principle Diagram

\section{LC Single Tuned Filter Design}

In Figure 3 LC single tuned filter, with the aid of power capacitor compensation, by designing the parameters of the reactor and resistance, to build a more passive LC resonance filter branch, respectively, on the bus in 3, 5, 7, 11 and 13 main harmonic suppression. For LC resonance filter, adjust the controllable switching device of LC branch, the connected branch of $\mathrm{L}, \mathrm{C}$ value in the corresponding harmonic frequency resonance point, become a low impedance to harmonic loop channel, reduce the harmonic current of the main loop of the busbar injection, in order to achieve the device itself to absorb harmonic current and reduce the system voltage distortion rate [5]. The filtering circuit of this system by the filter capacitor, filter reactor and controllable switching device, the controller can according to need to suppress one harmonic current and reactive power control device to control.

In order to ensure the required filter out of 3, 5, 7, 11, 13 times harmonic respectively $f_{n}=50 \mathrm{nHz} \quad(n=3,5,7,11,13)$ the resonance frequency points, two resonant state, need to calculate and determine the harmonic component to filter out $X_{L}=X_{C}$ times of the value of the capacitance and filter reactor.

Set to determine capacitor capacity of $Q_{C}$ (Kvar), the corresponding capacitive reactance is $X_{C}=\frac{V^{2}}{Q_{C}} \times 10^{-3}$, at this time in order to filter out $\mathrm{n}$ time harmonic, need to select the reactor inductance value is:

$$
X_{L}=\frac{X_{c}}{n^{2}}
$$


Among them: the resistance of the reactor $R=\frac{X_{n}}{Q}$, characteristics of resistance in type $X_{n}=\sqrt{X_{L} X_{C}}, Q$ for the filter quality factor, general take: $30<Q<100$.

Because this system is key to filter out 3,5, 7, 11, 13 harmonics, so the filter in the filter because of 5 , each branch selection calculation of corresponding parameters value as shown in Table 2.

Table 2. Filter Parameters

\begin{tabular}{|c|c|c|c|c|}
\hline branch & $\begin{array}{c}\text { Harmoni } \\
\text { c frequency }\end{array}$ & $\begin{array}{l}\text { Amount of } \\
\text { reactive power } \\
\text { KVar) }\end{array}$ & $\begin{array}{l}\text { Inductance } \\
\text { value }(m H)\end{array}$ & $\begin{array}{l}\text { Reactor resistance } \\
\text { inductance value }(\Omega \\
)\end{array}$ \\
\hline 1 & 3 & 240 & 0.64 & 0.2 \\
\hline 2 & 5 & 120 & 0.76 & 0.4 \\
\hline 3 & 7 & 120 & 0.55 & 0.4 \\
\hline 4 & 11 & 120 & 0.35 & 0.4 \\
\hline 5 & 13 & 60 & 0.59 & 0.8 \\
\hline
\end{tabular}

\section{Sectional Compensation Control Mode}

The second and following pages should begin 1.0 inch $(2.54 \mathrm{~cm})$ from the top edge. On all pages, the bottom margin should be 1-3/16 inches $(2.86 \mathrm{~cm})$ from the bottom edge of the page for $8.5 \times 11$-inch paper; for A4 paper, approximately 1-5/8 inches $(4.13 \mathrm{~cm})$ from the bottom edge of the page.

The computed in front of each section of the largest known compensation capacity is $660 \mathrm{KVAR}$, namely every $220 \mathrm{KVAR}$, phase compensation points is composed of 11 BSMJ0.4-20-3 capacitors, due to the difference of load operation condition, every moment need compensation capacity values are different, so each phase compensation capacitance can be divided into four groups, each group capacity by 8421 encoding connection, which respectively 20,40,80,80 KVAR, respectively in each group by $T_{1}, T_{2}$, $T_{3}, T_{4}$, and other four SCR control cutting, so you can form 12 kinds of sectional control mode, as shown in table 3 , cutting conditions by setting the power by numerical $\cos \varphi_{1}$ and bus $\cos \varphi_{c}$ compared to determine the actual power factor.

Table 3. Sectional Control Schema Table

\begin{tabular}{|c|c|c|c|c|c|c|c|}
\hline \multirow{2}{*}{$\begin{array}{l}\text { Control } \\
\text { mode }\end{array}$} & \multirow{2}{*}{$\begin{array}{l}\text { shunt } \\
\text { capacita } \\
\text { nc } \\
\text { number }\end{array}$} & \multirow{2}{*}{$\begin{array}{l}\text { Compensati } \\
\text { on capacity } \\
(\mathrm{KVAR} \\
\text { ( }\end{array}$} & \multicolumn{4}{|c|}{ Switching devices status } & \multirow{2}{*}{ Switching conditions } \\
\hline & & & $T_{1}$ & $T_{2}$ & $T_{3}$ & $T_{4}$ & \\
\hline 1 & 0 & 0 & off & off & off & off & $\cos \varphi_{c}>\cos \varphi_{1}$ \\
\hline 2 & 1 & 20 & on & off & off & off & $0.96 \leq \cos \varphi_{c}<\cos \varphi_{1}$ \\
\hline 3 & 2 & 40 & off & on & off & off & $0.94 \leq \cos \varphi_{c}<\cos \varphi_{1}$ \\
\hline 4 & 3 & 60 & on & on & off & off & $0.92 \leq \cos \varphi_{c}<\cos \varphi_{1}$ \\
\hline 5 & 4 & 80 & off & off & off & on & $0.90 \leq \cos \varphi_{c}<\cos \varphi_{1}$ \\
\hline 6 & 5 & 100 & on & off & on & off & $0.88 \leq \cos \varphi_{c}<\cos \varphi_{1}$ \\
\hline 7 & 6 & 120 & off & on & on & off & $0.86 \leq \cos \varphi_{c}<\cos \varphi_{1}$ \\
\hline
\end{tabular}




\begin{tabular}{|l|l|l|l|l|l|l|l|}
\hline 8 & 7 & 140 & on & on & \multicolumn{1}{|l|}{ on } & off & $0.84 \leq \cos \varphi_{c}<\cos \varphi_{1}$ \\
\hline 9 & 8 & 160 & off & off & on & on & $0.82 \leq \cos \varphi_{c}<\cos \varphi_{1}$ \\
\hline 10 & 9 & 180 & on & off & on & on & $0.80 \leq \cos \varphi_{c}<\cos \varphi_{1}$ \\
\hline 11 & 10 & 200 & off & on & on & on & $0.70 \leq \cos \varphi_{c}<\cos \varphi_{1}$ \\
\hline 12 & 11 & 220 & on & on & on & on & $0.7>\cos \varphi_{c}$, \\
& & & & & & & $0.7<\cos \varphi_{1}$, \\
\hline
\end{tabular}

\section{The Experimental Results and Conclusions}

Wherever Times New Roman is specified, Times Roman, or Times may be used. If neither is available on your word processor, please use the font closest in appearance to Times New Roman that you have access to. Please avoid using bitmapped fonts if possible. True-Type 1 fonts are preferred.

System put into operation in early June 2010, Figure 4 is the compensation bus in front of the phase current waveforms, obviously appear distortion, odd harmonic current content, and Figure 5 and Figure 6 is the bus after compensation phase current and power factor, , application structure shows that the equipment has experienced the start/stop, load increase and decrease, assessment of impact load and other situations, but the compensation device has stable operation, the instrument shows more than normal, the power factor is 0.85 , the main harmonic fell $5 \%$, bus phase voltage to $227 \mathrm{v}$, brought direct economic benefits for the enterprise.

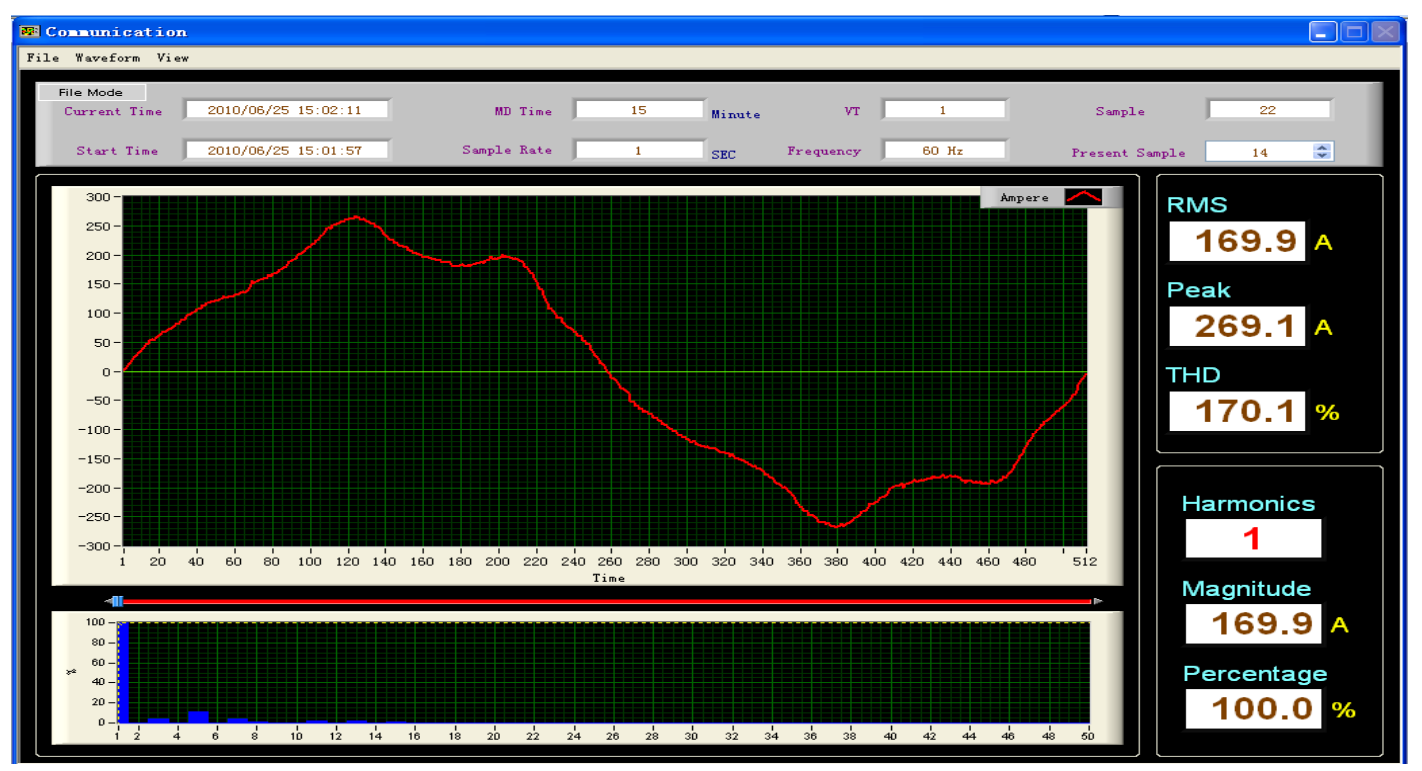

Figure 4. Compensation before the Phase Current Waveform 


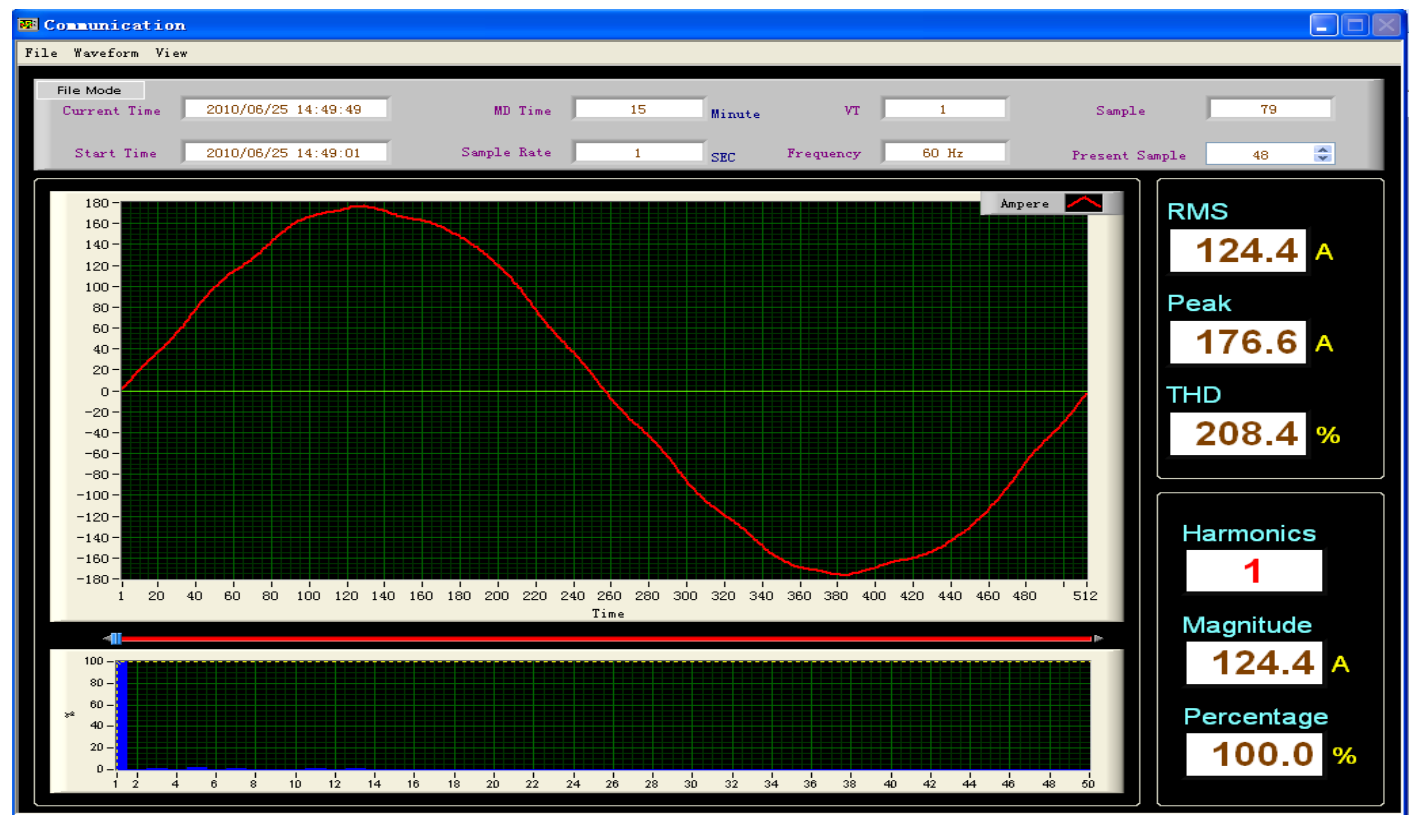

Figure 5. Compensation after the Phase Current Waveforms

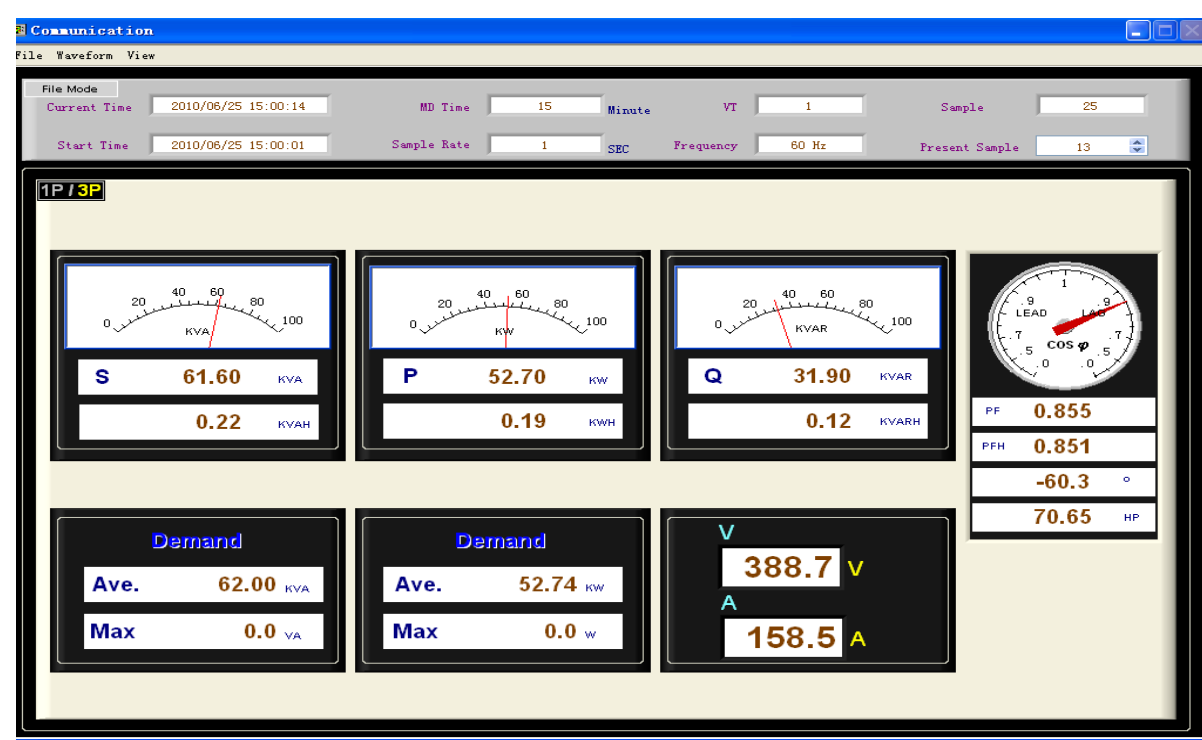

Figure 6. Compensation of Power Factor

\section{References}

[1] W. Xu, "A three-phase model", Wang Yue compiled, Harmonic suppression and reactive power compensation $[\mathrm{M}]$, Machinery industry press, vol. 1, (2009).

[2] L. Weixun compiled, "Modern power electronic technology [M]", Machinery industry press, vol. 10, (2011).

[3] D. Wang, S. Chen, J. Huang and S. Yan, "Based on the energy balance of the active principle of shunt active filter control method [J]", Journal of electrotechnics, vol. 12, no. 2, (2004), pp. 89-92.

[4] X. Hong, X. Ding and H. Yang, "Consider SVC static model of reactive power optimization research [J]", Electric logging and instrumentation, vol. 50, no. 4, (2013), pp. 101-106.

[5] T. Nakajima, "Operating Experiences of STATCOMs and a Three-Terminal HVDC System Using Voltage Sourced Converters in Japan", Proceedings of 2002 IEEE Transmission and Distribution Conference and Exhibition, vol. 2, (2002), pp. 1387-1392.

[6] W. S. Allen, K. B. Brent, P. D. L. J. James, J. H. David and H. Christopher, "A \pm 150 Mar STATCOM for Northeast Unilities 'Glenbrook Substation”, Proceedings of 2003 Power Engineering Society General Meeting, vol. 3, (2003), pp. 1834-1839. 
International Journal of Hybrid Information Technology

Vol.8, No.1 (2015) 